\title{
Identification of porcine circovirus type 2 (PCV2), type 3 (PCV3) and porcine parvovirus (PPV) in swine by multiplex PCR test
}

\author{
Thoai K. $\operatorname{Tran}^{1}$, Trang T. T Nguyen ${ }^{1}$, Hiep L. X. Vu ${ }^{2}$, \& Phat X. Dinh ${ }^{1 *}$ \\ ${ }^{1}$ Faculty of Biological Sciences, Nong Lam University, Ho Chi Minh City, Vietnam \\ ${ }^{2}$ Nebraska Center for Virology, and School of Veterinary Medicine and Biomedical Sciences, \\ University of Nebraska Lincoln, Nebraska, USA
}

ARTICLE INFO
Research Paper
Received: April 22, 2021
Revised: May 21, 2021
Accepted: June 01, 2021
Keywords
mPCR
PCV2
PCV3
PPV
Swine
*Corresponding author
Dinh Xuan Phat
Email: dinhxuanphat@hcmuaf.edu.vn

Cited as: Tran, T. K., Nguyen, T. T. T., Vu, H. L. X., \& Dinh, P. X. (2021). Identification of porcine circovirus type 2 (PCV2), type 3 (PCV3) and porcine parvovirus (PPV) in swine by multiplex PCR test. The Journal of Agriculture and Development 20(3), 11-17.

\section{Introduction}

Reproductive disorders are among the most concerned syndromes in sow herds, causing huge economic losses to swine producers. Many infectious pathogens are involved in the problems, including porcine parvovirus (PPV), porcine circovirus type 2 (PCV2) and porcine circovirus type 3 (PCV3), a newly discovered viral pathogen (Palinski et al., 2016).

Porcine circovirus type 2 and type 3 are nonenveloped and single-circular DNA viruses that belong to the family Circoviridae (Tisciier et al., 1986; Palinski et al., 2016). Porcine circovirus type 2 has been demonstrated to play significant roles in different swine syndromes such as postweaning multisystemic wasting syndrome (PMWS), porcine dermatitis and nephropathy syndrome (PDNS), or porcine circovirus associated diseases (PCVAD) in general (Allan et al., 1999; Allan et al., 2000; Rosell et al., 2000). The virus was first identified in western Canada in a case of wasting disease using electron microscopy, immunohistochemical, and in-situ hybridization methods (Ellis et al., 1998). Later, various publications illustrated the circulation and the pathogenesis of PCV2 in abortion cases or weak piglets at birth (West et al., 1999; Calsamiglia et al., 
2007; Oropeza-Moe et al., 2017). Porcine circovirus type 3 was recently detected in a case of PDNS syndrome in a sow farm in North Carolina (USA) (Palinski et al., 2016). The virus was found in the skin, kidneys, lungs, and lymph nodes of the affected pigs without the existence of PCV2. From this observation, PCV3 was also suspected to play a pathogenic role in swine, especially in the sow herds, although the evidence of its pathogenesis remains to be elusive. In addition, another virus in the list of causative agents for reproductive disorders in swine is PPV, a member of the Parvoviridae family, that was identified at the end of the 1960s (Cartwright et al., 1967; Cartwright et al., 1969; Johnson \& Collings, 1969). Typical manifestations associated with a PPV infection in pregnant sows are collectively identified as SMEDI syndrome which includes stillbirths, mummification, embryonic death, and infertility. These viruses are currently circulating in Vietnam and cause significant losses (Huynh et al., 2014; Dinh et al., 2021). Co-infection among these viruses may result in a different impact on the swine farms. Co-infection of swine with PCV2 and PCV3 does not result in significantly enhanced disease outcomes compared to individual infection with one of these two viruses (Wozniak et al., 2019). However, co-infection of swine with PCV2 and PPV led to the increased viremia level of PCV2 (Milek et al., 2020).

Several conventional and real-time PCRs have been developed for molecular diagnosis of these three viruses (Chen et al., 2009; Zhao et al., 2010; Yang et al., 2019). However, those PCRs are designed for the detection of a single or double pathogens at a time. In the present study, we report the development and validation of a $\mathrm{mPCR}$ that allows simultaneous detection of these three viruses in field samples.

\section{Materials and Methods}

\subsection{Controls and clinical samples}

Positive controls: DNA fragments of PCV3 Cap gene and PPV NS1 gene were synthesized by Integrated DNA Technologies (IDT - USA) based on the sequences of PCV3 (MH184542.1) and PPV (MK993540.1), respectively. The DNA template of PCV2 was originally obtained from a field isolate followed by sequencing confirmation. The resulting sequence exhibited $99.72 \%$ identity to the previously reported PCV2 (Gene Accession no. LC383449.1).

Unrelated DNA from other pathogens used for specificity evaluation: bacteria and viruses that are commonly present in swine farm environment and potentially contaminated into the samples were used to confirm the specificity of the mPCR. Staphylococcus aureus (ATCC 6338) and Escherichia coli (ATCC 25922) were offered by Sanphar Vietnam laboratory (belonging to Erber group, Austria); Streptococcus suis and Clostridium perfringens were obtained from a previous study (Nguyen et al., 2018). The bacterial DNA was extracted with phenol-chloroformisoamyl alcohol (25:24:1) solution (Cat\#P1037, Sigma; Cat\#25666, Merck). Pseudorabies virus $g E$ gene was synthesized by Integrated DNA Technologies (IDT - USA).

Field samples: Ninety-four serum samples from sows were collected and used to evaluate this mPCR procedure. These sow farms were located in the South of Vietnam. Each serum sample was pooled from five individual sows. All samples were submitted to the laboratory and the senders signed an agreement for the laboratory to use the result data for teaching and publication. The infectious status of these 94 samples was predetermined by using commercial real-time PCR kits or master mix, as per the manufacturers' instructions. The real-time kits used for detection of PCV2, PPV and PCV3 were PowerChekTM PCV2 real-time PCR kit (Cat\#R0809, Primerdesign), PowerChekTM ADV/PPV real-time PCR kit (Cat\#R0832, Primerdesign) and Luna ${ }^{\circledR}$ Universal qPCR Master Mix (Cat\#M3003S, NEB), respectively.

\subsection{DNA preparation from clinical samples}

The DNA was extracted from test serum samples by using the advanced phenol-chloroform method. The extracted DNA was stored at $-20^{\circ} \mathrm{C}$ for subsequent assays.

\subsection{Primers}

The primers used in this study are listed in Table 1. For PCV2, primers were designed based on the consensus of 65 PCV2 Cap gene sequences in the NCBI GenBank with a PCR product of 702 bp. For PPV, primers were designed based on the consensus of 67 PPV NS1 sequences in the NCBI GenBank with an expected product of 380 bp. Lastly, for PCV3, primers were obtained from 
Table 1. Primer sequences and estimated product sizes

\begin{tabular}{lcclcc}
\hline Virus & Primers & Gene Primer sequences $\left(5^{\prime}-3^{\prime}\right)$ & $\begin{array}{c}\text { Product } \\
\text { size (bp) }\end{array}$ & Reference \\
\hline PCV2 & PCV2 & Cap & $\begin{array}{l}\text { F:ATGACGTATCCAAGGAGGCG } \\
\text { R: TTAAGGGTTAAGTGGGGGGTC }\end{array}$ & 702 & Present study \\
PCV3 & PCV3 & Cap & $\begin{array}{l}\text { F: TTCCGGGACATAAATGCT } \\
\text { R: GGGCACACAGCCATAGAT }\end{array}$ & 267 & Chen et al., 2017 \\
PPV & PPV & NS1 & $\begin{array}{l}\text { F: GCTTTAGCCTTGGAGCCGTGGA } \\
\text { R: CGTGTTCTTTTGCTGCGGCGTC }\end{array}$ & 380 & Present study \\
\hline
\end{tabular}

Chen et al. (2017). They were designed based on the PCV3 Cap gene with a product size of 267 bp.

\subsection{Multiplex PCR (mPCR)}

After multiple rounds of optimization, a primer mix containing three primer pairs were created at a mixing ratio of $1 \mathrm{PPV}: 2 \mathrm{PCV} 2: 4 \mathrm{PCV} 3$. Accordingly, the final concentrations of the PPV, $\mathrm{PCV} 2$ and PCV3 primer pairs in the mixture were $0.2 \mu \mathrm{M}, 0.4 \mu \mathrm{M}, 0.8 \mu \mathrm{M}$, respectively. The $\mathrm{mPCR}$ was performed in a $20 \mu \mathrm{L}$ reaction volume containing $10 \mu \mathrm{L}$ of DreamTaq 2X (Cat\#K1072, No MAN0012702, Thermo Scientific), $1.4 \mu \mathrm{L}$ of the primer mix, $3 \mu \mathrm{L}$ DNA template, and 5.6 $\mu \mathrm{L}$ of nuclease free water (Thermo Fisher). After initial denaturation at $94^{\circ} \mathrm{C}$ for $5 \mathrm{~min}, 35 \mathrm{cy}-$ cles were conducted at $94^{\circ} \mathrm{C}$ for $30 \mathrm{sec}, 56^{\circ} \mathrm{C}$ for $30 \mathrm{sec}$, and $72^{\circ} \mathrm{C}$ for $40 \mathrm{sec}$, followed by a final extension at $72^{\circ} \mathrm{C}$ for $5 \mathrm{~min}$. The amplified products were then analyzed by electrophoresis in a $1.5 \%(\mathrm{w} / \mathrm{v})$ agarose gel in $1 \mathrm{X}$ Tris-Boric-EDTA (TBE) containing Midori Green Advance DNA stain (Cat\#MG04, Nippon Genetics). The standard DNA (Cat\#10787018, Invitrogen) was included in each DNA gel electrophoresis to indicate the PCR product size.

\subsection{Evaluation of the specificity of the MPCR}

The target viruses of this study can be found in blood, saliva, feces, vulval discharge in live pigs. In disease surveillance, these types of samples are favored due to the less invasive advantages. However, sampling procedures in practice are prone to contamination with other bacteria or viruses popularly distributed in pig farms. Therefore, genomic DNA of $S$. aureus, E. coli, S. suis, C. perfringens and PRV $g E$ gene were used as templates in the $\mathrm{mPCR}$ to determine the specificity of the test. The concentration of DNA templates used in the reaction was $30 \mathrm{ng}$ per reaction in the cases of bacterial target and $10^{8}$ copies per reaction in the case of $g E$ gene.

\subsection{Evaluation of the detection limit of the mPCR}

Ten-fold serial dilutions of each positive control DNA templates ranging from $10^{7}$ to $10^{0}$ copies were used as the DNA template in the $\mathrm{mPCR}$ to determine its limit of detection. The minimum number of template copies that enable successful amplification of all products was considered as the limit of detection of the mPCR.

\subsection{DNA sequencing}

Sequencing of each PCR product was performed by using both forward and reverse primers used in the corresponding PCR (Table 1). The sequencing results were aligned with the reference PCV2 (accession no. MH470234.1), PCV3 (accession no. MK058529.1) and PPV (accession no. MK378155.1) using Clustal Omega program.

\section{Results}

\subsection{Optimal conditions for the mPCR}

Before the optimal ratio of primers for $\mathrm{mPCR}$ was achieved, each primer pair was tested for its performance in single PCR (sPCR) at different annealing temperatures. Gel analysis indicated that only one DNA product was generated in each sPCR, with the product sizes of $267 \mathrm{bp}$ for PCV3, 380 bp for PPV and 702 bp for PCV2 (Figure 1). It appeared that the three primer pairs worked well at the annealing temperatures between $52^{\circ} \mathrm{C}$ $-58^{\circ} \mathrm{C}$.

Subsequently, the annealing temperature of $56^{\circ} \mathrm{C}$ was chosen for mPCR. As shown in Figure 2 , the $\mathrm{mPCR}$ produced three amplicons that were 
clearly visible and easily distinguishable. Importantly, the sizes of the amplicons were as expected and were similar to the ones observed in the corresponding sPCRs (Figure 2). These three products in $\mathrm{mPCR}$ were recovered from agarose gel and subjected to sequencing. The results confirmed that the three PCR amplicons from the mPCR aligned well with the three respective target DNA sequences, indicating that the primer pairs functioned as anticipated.

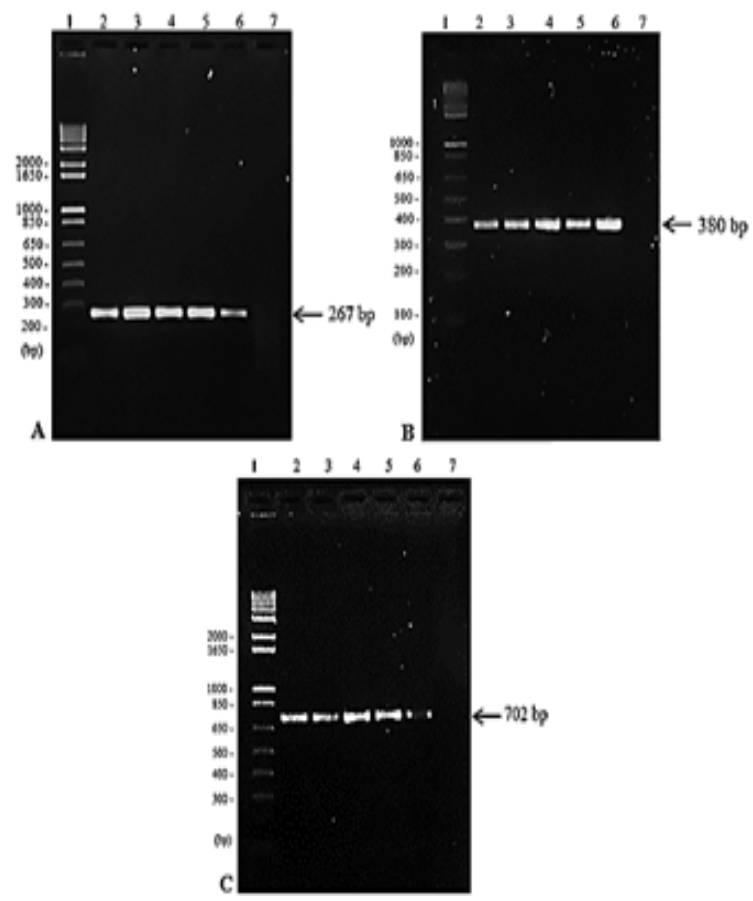

Figure 1. Optimization of annealing temperature in s-PCR. (A) PCV3, (B) PPV, (C) PCV2. (Lane 1): DNA ladder $1 \mathrm{~Kb}$ plus, (Lane 2): $50^{\circ} \mathrm{C}$, (Lane 3 ): $52^{\circ} \mathrm{C}$, (Lane 4$): 54^{\circ} \mathrm{C}$, (Lane 5 ): $56^{\circ} \mathrm{C}$, (Lane 6$): 58^{\circ} \mathrm{C}$, (Lane 7 ): negative control with pure water. The thermal cycling conditions were $94^{\circ} \mathrm{C} / 5 \mathrm{~min} ; 35$ cycles of $94^{\circ} \mathrm{C} / 30 \mathrm{sec}, 50-58^{\circ} \mathrm{C} / 30 \mathrm{sec}$ and $72^{\circ} \mathrm{C} / 40 \mathrm{sec}$, a final extension at $72^{\circ} \mathrm{C} / 5 \mathrm{~min}$.

\subsection{Specificity and detection limit of the mPCR}

Next, we wanted to evaluate the specificity of this mPCR by running the assay with DNA templates extracted from bacteria and viruses commonly present in swine farm environment including Staphylococcus aureus, Escherichia coli, Streptococcus suis, Clostridium perfringens and Pseudorabies virus. Results showed that the three primer pairs did not cross-react with any of

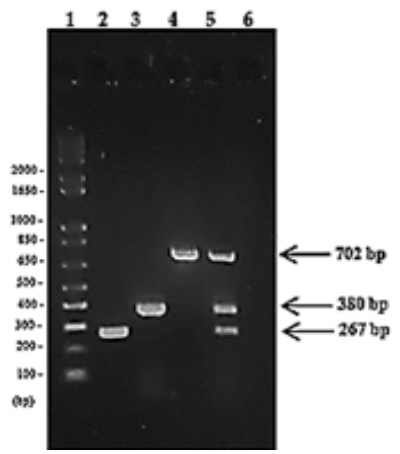

Figure 2. Products of $\mathrm{sPCRs}$ and $\mathrm{mPCR}$. (Lane 1): DNA ladder, (Lane 2): PCV3 267 bp, (Lane 3): PPV 380 bp, (Lane 4): PCV2 702 bp, (Lane 5): $\mathrm{mPCR}$ of all three targets, (Lane 6): negative control with pure water. The thermal cycling conditions were $94^{\circ} \mathrm{C} / 5 \mathrm{~min} ; 35$ cycles of $94^{\circ} \mathrm{C} / 30 \mathrm{sec}, 56^{\circ} \mathrm{C} / 30$ sec and $72^{\circ} \mathrm{C} / 40 \mathrm{sec}$, a final extension at $72^{\circ} \mathrm{C} / 5 \mathrm{~min}$.

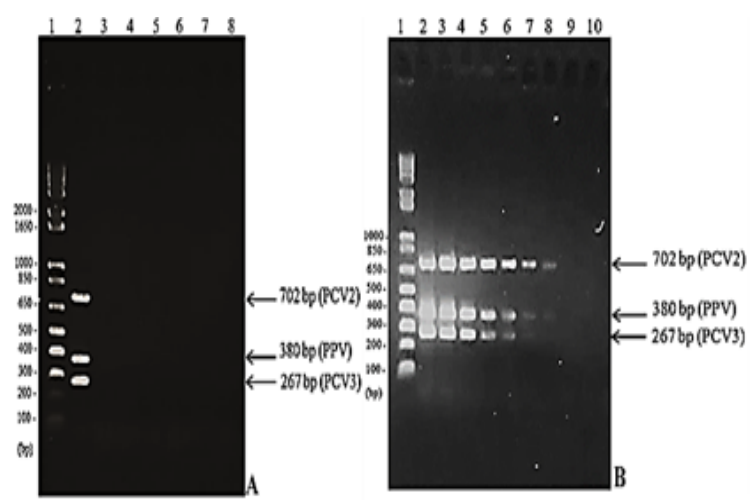

Figure 3. Specificity and detection limit of the mPCR. (A) Result of specificity test. (Lane 1): DNA ladder, (Lane 2): positive control, (Lane 3): E. coli, (Lane 4): Streptococcus suis, (Lane 5): Staphylococcus aureus, (Lane 6): C. perfringens, (Lane 7): Pseudorabies virus, (Lane 8): negative control. (B) Detection limit of the mPCR. (Lane 1): DNA ladder, (Lane 29): DNA template of PCV2, PCV3 and PPV at $10^{7}$ $10^{0}$ copies/reaction; (Lane 10): negative control with pure water.

these DNA templates (Figure 3A), indicating the mPCR established in this study was highly specific.

We then evaluated the limit of detection of the mPCR by performing the assay with a set of 10fold serially diluted positive control DNA samples with the copy numbers ranging from $10^{7}$ to $10^{0}$ copies per reaction. As shown in Figure 3B, three distinct DNA bands at the expected size were observed at the concentration of $10^{2}$ copies per reaction. It demonstrated that this $\mathrm{mPCR}$ 
could detect the viral genes at the limit of 100 copies/gene/reaction.

\subsection{Performance of the $\mathrm{mPCR}$ with clinical samples}

The ultimate aim of this experiment was to evaluate the diagnostic performance of the $\mathrm{mPCR}$ using field samples. A total of 94 sow serum samples whose infectious status was predetermined by commercial single-target real-time PCR kits were used to evaluate the established $\mathrm{mPCR}$. The DNA electrophoresis of $\mathrm{mPCR}$ results was partially illustrated in Figure 4 and the sample that was infected with one single pathogen such as PPV (Figure 4A, lane 6) or samples that were dually infected with two pathogens (Figure 4B, lane 4 and 11) or three pathogens (Figure 4A, lane 8 and 10). The $\mathrm{mPCR}$ results matched completely with the results generated by commercial realtime PCR. The infection rates for PCV2, PCV3 and PPV in these 94 samples were $43.6 \%, 39.4 \%$ and $55.3 \%$, respectively. Combined infection of the three tested viruses (PCV2, PCV3 and PPV) was $17.0 \%$ while the dual infection between PCV2 and PCV3, PCV3 and PPV, or PCV2 and PPV were $7.4 \%, 5.3 \%$, and $11.7 \%$, respectively.

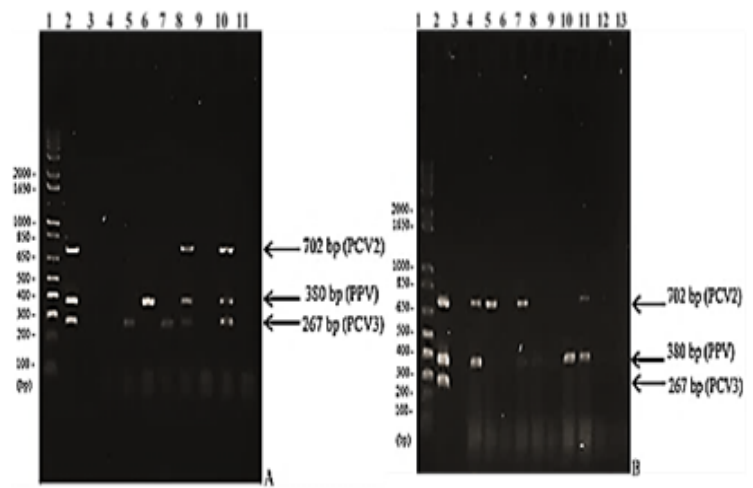

Figure 4. Diagnosis of PCV2, PCV3, PPV in clinical samples. (A) mPCR result of samples 1-9. (Lane 1): DNA ladder; (Lane 2): positive control; (Lane 3): negative control. (Lane 4 - 11): samples 1 to 9 . (B) mPCR result of samples 10-19. (Lane 1): DNA ladder; (Lane 2): positive control; (Lane 3): negative control with pure water. (Lane 4 - 13): samples 10-19.

\subsection{Sequence analysis of the PCR amplicons}

To further confirm the specificity of the mPCR assay, PCR products of PPV, PCV3 and PCV2 amplified from the field samples were excised from the agarose gel and subjected to DNA sequencing. The resulting sequences exhibited $100 \%, 98.88 \%, 98.95 \%$ identity to the reference sequences for PCV2 (MH470234.1); PCV3 (MK058529.1) and PPV (MK378155.1), respectively.

\section{Discussion}

Swine reproductive failure is a common disorder in sow herds in Vietnam at present. Various pathogens can be found in such cases including classical swine fever virus, Aujeszky's disease virus, PRRSV (Porcine reproductive and respiratory syndrome virus), PPV, PCV2, PCV3 and some bacteria (Christianson, 1992; Dinh et al., 2021). Currently, single real-time PCRs are available for molecular detection of these viruses. Nevertheless, single real-time PCRs are relatively expensive, thereby deterring swine producers from using these services. Multiplex PCRs can significantly reduce the cost spent in single PCR for each target. Technically, it is easier to develop a multiplex PCR for viruses that are in the same category of either RNA or DNA genome. Therefore, the goal of this study was to develop a quick and reliable $\mathrm{mPCR}$ that allows simultaneous detection of PCV2, PCV3 and PPV, the three DNA viruses that are commonly involved in reproductive failure.

Since its initial identification in the US (Palinski et al., 2016), PCV3 has been found in various pig-producing countries. The $39.4 \%$ detection rate for PCV3 in our study was also comparable to other reports elsewhere, such as $44.2 \%$ in Korea (Kwon et al., 2017); 31.18\% in Central China (Xu et al., 2018); 50\% in Germany (Prinz et al., 2019); $56.4 \%, 37.4 \%, 14.8 \%$ in Denmark, Italy, Spain, respectively (Franzo et al., 2018); $61.1 \%$ in United States (Arruda et al., 2019); and $47.8 \%$ in Brazil (Saraiva et al., 2019). Concurrent infections between PCV2 and other bacteria or viruses have been reported widely in swine herds (Ouyang et al., 2019; Dinh et al., 2021). One of the plausible reasons for this is that PCV2 can suppress the host immune system, therefore rendering the host more susceptible to infections with other microorganisms. The PPV is one of the common swine pathogens that are detected in PCV2 infected pigs (Ouyang et al., 2019). Previous studies showed that co-infections of pigs with PCV2 and PPV were more effective in inducing PMWS disease than coinfection between 
PCV2 and other pathogens (Milek et al., 2020). Consequently, PPV could be used in combination with PCV2 to induce PMWS in experimental studies (Palinski et al., 2016). Coinfection of PCV2 and PCV3 is also commonly observed. Several surveillances from China have reported the PCV2/PCV3 co-infection rates varying from 27.6 - 39.39\% (Ouyang et al., 2019). Those numbers were higher than what we found in this study (7.4\%). In addition, it has been demonstrated that PCV2, PCV3 and PPV are endemic in Vietnam (Huynh et al., 2015; Pham et al., 2017; Nguyen et al., 2020), but the co-infection rates of these 3 viruses in sow herds have not been studied. Our preliminary demonstration of $17 \%$ of sow samples to be simultaneously positive for these three viruses illustrated the complex prevalence of various pathogens involved in porcine reproductive syndrome in Vietnam and highlighted the need for further investigations for a better understanding and control strategies.

The detection limit of our mPCR is 100 copies for each target gene per reaction. Liu et al. (2015) established a mPCR to detect and differentiate PCV2, PRRSV, PPV and Pseudorabies virus in pigs with PMWS manifestation. The authors reported that the sensitivity of their $\mathrm{mPCR}$ was $4.0 \times 10^{3}$ and $3.0 \times 10^{2}$ copies to PCV2 and PPV, respectively. Recently, Yang et al. (2018) developed a mPCR for simultaneous detection of PCV1, PCV2 and PCV3 with the detection limit of 50 copies of each target gene per reaction. Thus, our mPCR reported in this communication possesses a fairly good detection limit and certainly can be useful for pathogen monitoring in the field or used for predetermination of pathogen occurrence before further viral analysis of field samples.

\section{Conclusions}

In summary, we have successfully developed and validated a mPCR assay to simultaneously detect PCV2, PCV3 and PPV, the three common swine DNA viruses in field samples. This mPCR should provide a quick and reliable molecular diagnostic tool for reproductive failure in sow herds.

\section{References}

Allan, G. M., McNeilly, E., Kennedy, S., Meehan, B., Moffett, D., Malone, F., Ellis, J., \& Krakowka, S. (2000).
PCV-2-associated PDNS in Northern Ireland in 1990. Porcine dermatitis and nephropathy syndrome. Veterinary Record 146(24), 711-712.

Allan, G. M., McNeilly, F., Meehan, B. M., Kennedy, S., Mackie, D. P., Ellis, J. A., Clark, E. G., Espuna, E., Saubi, N., \& Riera, P. (1999). Isolation and characterisation of circoviruses from pigs with wasting syndromes in Spain, Denmark and Northern Ireland. Veterinary Microbiology 66(2), 115-123.

Arruda, B., Piñeyro, P., Derscheida, R., Hause, B., Byers, E., Dion, K., Long, D., Sievers, D., Tangen, J., Williams, T., \& Schwartz, K. (2019). PCV3-associated disease in the United States swine herd. Emerging $M i$ crobes \& Infections 8(1), 684-698.

Calsamiglia, M., Fraile, L., Espinal, A., Cuxart, A., Seminati, C., Martín, M., Mateu, E., Domingo, M., \& Segalés, J. (2007). Sow porcine circovirus type 2 (PCV2) status effect on litter mortality in postweaning multisystemic wasting syndrome (PMWS). Research in Veterinary Science 82(3), 299-304.

Cartwright, S. F., \& Huck, R. A. (1967). Viruses isolated in association with herd infertility abortions and stillbirths in pigs. Veterinary Record 81(1967), 196-197.

Cartwright, S. F., Lucas, M., \& Huck, R. A. (1969). A small haemagglutinating porcine DNA virus: I. Isolation and properties. The Journal of Comparative Pathology 79(3), 371-377.

Chen, G. H., Mai, K. J., Zhou, L., Wu, R. T., Tabg, X. Y., Wu, J. L., He, L. L., Lan, T., Xie, Q. M., Sun, Y., \& Ma, J. Y. (2017). Detection and genome sequencing of porcine circovirus 3 in neonatal pigs with congenital tremors in South China. Transboundary and Emerging Diseases 64(6), 1650-1654.

Chen, H. Y., Li, X. K., Cui, B. A., Wei, Z. Y., Li, X. S., Wang, Y. B., Zhao, L., \& Wang, X. Y. (2009). A TaqMan-based real-time polymerase chain reaction for the detection of porcine parvovirus. Journal of Virological Methods 156(1-2), 84-88.

Christianson, W. T. (1992). Stillbirths, mummies, abortions, and early embryonic death. Veterinary Clinics of North America: Food Animal Practice 8(3), 623-639.

Dinh, P. X., Nguyen, N. M., Nguyen, T. H., Tran, V. H., Tran, Q. D., Dang, K. H., Vo, D. T., Le, H. T., Nguyen, N. T. T., Nguyen, T. T., \& Do, D. T. (2021). Porcine circovirus genotypes and their copathogens in pigs with respiratory disease in southern provinces of Vietnam. Archives of Virology 166(2), 403-411.

Ellis, J., Hassard, L., Clark, E., Harding, J., Allan, G., Willson, P., Strokappe, J., Martin, K., McNeilly, F., \& Meehan, B. (1998). Isolation of circovirus from lesions of pigs with postweaning multisystemic wasting syndrome. Canadian Veterinary Journal 39(1), 44-51.

Franzo, G., Legnardi, M., Hjulsager, C. K., Klaumann, F., Larsen, L. E., Segales, J., \& Drigo, M. (2018). Fullgenome sequencing of porcine circovirus 3 field strains from Denmark, Italy and Spain demonstrates a high within-Europe genetic heterogeneity. Transboundary and Emerging Diseases 65(3), 602-606. 
Huynh, T. M. L., Le, V. P., Nguyen, V. G., \& Trinh, D. T. (2015). Variety selection porcine circovirus type 2 (PCV2) for producing vaccines against piglets. Journal of Scientific Research and Development 13, 406-415.

Huynh, T. M., Nguyen, B. H., Nguyen, V. G., Dang, H. A., Mai, T. N., Tran, T. H., Ngo, M. H., Le, V. T., Vu, T. N., Ta, T. K., Vo, V. H., Kim, H. K., \& Park, B. K. (2014). Phylogenetic and phylogeographic analyses of porcine circovirus type 2 among pig farms in Vietnam. Transboundary and Emerging Diseases 61(6), e25-34.

Johnson, R., \& Collings, D. (1969). Experimental infection of piglets and pregnant gilt with a parvovirus. Veterinary Record 85(16), 446-447.

Kwon, T., Yoo, S. J., Park, C. K., \& Lyoo, Y. S. (2017). Prevalence of novel porcine circovirus 3 in Korean pig populations. Veterinary Microbiology 207, 178-180.

Liu, J. K., Wei, C. H., Yang, X. Y., Dai, A. L., \& Li, X. H. (2015). Simultaneous detection and differentiation of porcine circovirus type 2 , type 2 porcine reproductive and respiratory syndrome virus, porcine parvovirus and pseudorabies virus in pigs with postweaning multisystemic wasting syndrome (PMWS) by multiplex PCR. The journal Veterinarski arhiv 85(5), 511-521.

Milek, D., Wozniak, A., Podgorska, K., \& Stadejek, T. (2020). Do porcine parvoviruses 1 through 7 (PPV1PPV7) have an impact on porcine circovirus type 2 (PCV2) viremia in pigs? Veterinary Microbiology 242, 108613.

Nguyen, D. H. M., Luong, Q. T. X., Hoang, P. T., Do, D. T. T., Tran, T. K., \& Dinh, P. X. (2018). Detecting toxin genes of Clostridium perfringens isolated from diarrhea piglets using multiplex PCR. The Journal of Agriculture and Development 17(6), 24-30.

Nguyen, V. G., Mai, T. N., Le, V. T., Vu, T. N., Vo, V. H., Ta, T. K. C., Vu, D. H., \& Huynh, T. M. L. (2020). Presence of porcine parvovirus 1 (PPV1) in domestic pigs in Ha Noi and the neighborhood. Vietnam Journal of Agricultural Sciences 18, 495-503.

Oropeza-Moe, M., Oropeza Delgado, A. J., \& Framstad, T. (2017). Porcine circovirus type 2 associated reproductive failure in a specific pathogen free (SPF) piglet producing herd in Norway: a case report. Porcine Health Management 3(1), 2-6.

Ouyang, T., Zhang, X., Liu, X., \& Ren, L. (2019). CoInfection of swine with porcine circovirus type 2 and other swine viruses. Viruses 11(2), 185.

Palinski, R., Piñeyro, P., Shang, P., Yuan, F., Guo, R., Fang, Y., Rui, G., Ying, F., Emily, B., \& Ben, M. H. (2016). A novel porcine circovirus distantly related to known circoviruses is associated with porcine dermatitis and nephropathy syndrome and reproductive failure. Journal of Virology 91(1), e01879-16.

Pham, H. Q., Nguyen, V. G., Nguyen, T. T. T., Pham, C. H., \& Huynh, T. M. L. (2017). Study the circulation of new viruses (porcine circovirus 3 - PCV3) in pigs raised in some northern provinces of Vietnam. Vietnam Journal of Agricultural Science 15(11), 1520-1528.
Prinz, C., Stillfried, M., Neubert, L. K., \& Denner, J. (2019). Detection of PCV3 in German wild boars. Virology Journal 16, (1), 25.

Rosell, C., Segales, J., Ramos-Vara, J. A., Folch, J. M., Rodriguez-Arrioja, G. M., Duran, C. O., Balasch, M., Plana-Duran, J., \& Domingo, M. (2000). Identification of porcine circovirus in tissues of pigs with porcine dermatitis and nephropathy syndrome. Veterinary Record 146(2), 40-43.

Saraiva, G. L., Vidigal, P. M. P., Assao, V. S., Fajardo, M. L. M., Loreto, A. L. S., Fietto, J. R. L., Bressan, G. C., Lobato, Z. I. P., Almeida, M. R. D., \& SilvaJúnior, A. (2019). Retrospective detection and genetic characterization of porcine circovirus 3 (PCV3) strains identified between 2006 and 2007 in Brazil. Viruses 11(3), 201.

Tisciier, I., Mields, W., Wolff, D., Vagt, M., \& Griem, W. (1986). Studies on epidemiology and pathogenicity of porcine circovirus. Archives of Virology 91(3-4), 271276.

West, K. H., Bystrom, J. M., Wojnarowicz, C., Shantz, N., Jacobson, M., \& Allan, G. M. (1999). Myocarditis and abortion associated with intrauterine infection of sows with porcine circovirus 2. Journal of Veterinary Diagnostic Investigation 11(6), 530-532.

Wozniak, A., Milek, D., Baska, P., \& Stadejek, T. (2019). Does porcine circovirus type 3 (PCV3) interfere with porcine circovirus type 2 (PCV2) vaccine efficacy? Transboundary and Emerging Diseases 66(4), 14541461.

Xu, P. L., Zhang, Y., Zhao, Y., Zheng, H. H., Han, H. Y., Zhang, H. X., Chen, H. Y., Yang, M. F., \& Zheng, L. L. (2018). Detection and phylogenetic analysis of porcine circovirus type 3 in central China. Transboundary and Emerging Diseases 65(5), 1163-1169.

Yang, K., Jiao, Z., Zhou, D., Guo, R., Duan, Z., Yuan, F., \& Tian, Y. (2018). Detection of porcine circoviruses in clinical specimens using multiplex PCR in Hubei, central China. PeerJ Preprints 6, e27145v1.

Yang, K., Jiao, Z., Zhou, D., Guo, R., Duan, Z., \& Tian, Y. (2019). Development of a multiplex PCR to detect and discriminate porcine circoviruses in clinical specimens. BMC Infectious Diseases 19, 778.

Zhao, K., Han, F., Zou, Y., Zhu, L., Li, C., Xu, Y., Zhang, C., Tan, F., Wang, J., Tao, S., He, X., Zhou, Z., \& Tang, X. (2010). Rapid detection of porcine circovirus type 2 using a TaqMan-based real-time PCR. Virology Journal 7, 374. 